\title{
La ilusión del orden: consideraciones sobre el mito habsbúrgico*
}

\author{
The illusion of order: observations on \\ the habsburgic myth
}

\author{
NURIA SÁNCHEZ MADRID \\ Universidad Complutense de Madrid \\ nuriasma@ucm.es
}

Recibido: 26-03-2012

Aceptado: 12-01-2013

«Man handelte in diesem Land [...] immer anders, als man dachte, oder dachte anders, als man handelte»

Musil, El hombre sin atributos, 8. «Kakania»

\section{Resumen}

El trabajo analiza la percepción y construcción de la crisis reconocible en algunos autores vinculados a la recreación del mito habsbúrgico, como S. Zweig, F. Werfel, J. Roth y R. Musil. En primer lugar, me ocupo de delimitar el alcance poético de las representaciones del Imperio en los dos primeros escritores, con especial atención a la noción de temporalidad y a la dinámica espiritual de la Mitteleuropa de finales del siglo XIX y comienzos del XX. En segundo lugar, plantearé de la

\footnotetext{
* Este trabajo ha sido realizado en el marco del Proyecto de Investigación Poetics of Selfhood: memory, imagination and narrativity (PTDC/MHC-FIL/4203/2012) del CFU, concedido por la Fundação de Ciência e Tecnologia del Gobierno de Portugal, y se inscribe en la recién iniciada en los Proyectos Naturaleza humana y comunidad (III). ¿Actualidad del humanismo e inactualidad del hombre? (FFI2013-46815-P) y Retóricas del Clasicismo. Los puntos de vista (contextos, premisas, mentalidades) (FFI2013-41410-P), concedidos ambos por el MINECO del Gobierno de España. Una primera versión del trabajo se presentó y discutió con el equipo participante en la Acción de cooperación entre Alemania y el Sur de Europa del DAAD, titulada Krise als strukturelle Signatur y coordinada por los profesores Ana Carrasco-Conde (UCM-UPM) y Christoph Asmuth (TU Berlin), durante los días 11, 12 y 13 de diciembre de 2013. Agradezco las observaciones recibidas por los participantes en el coloquio, y muy especialmente los siempre estimulantes comentarios de Ana Carrasco-Conde.
} 
mano de la escritura de Joseph Roth la ambivalencia de la idea de orden político, hacia el que se manifiesta una decidida adoración como fuente de sentido histórico, si bien al mismo tiempo se condenan los efectos del progreso tecnológico. Finalmente, la noción de razón insuficiente de Musil ofrecerá el marco para proceder a una experiencia de la crisis que no desemboque en el nihilismo. El propósito principal de este escrito es contribuir al estudio de la potencia poética de los modelos políticos e históricos, proponiendo una lectura de la conexión entre el Juicio, la poética y la historia.

Palabras clave: Mito habsbúrgico, crisis, filosofía de la historia, Stefan Zweig, Franz Werfel, Joseph Roth, Rober Musil.

\begin{abstract}
The paper tackles the construction and perception of crisis in some prominent authors linked to the recreation of the Habsburg myth, as S. Zweig, F. Werfel, J. Roth and R. Musil. First, I attempt to define the scope of poetic representations of the Empire in the first two writers, taking especially into appraise the notion of temporality and spiritual dynamics of Mitteleuropa in late nineteenth and early twentieth centuries. Secondly, we will focus on Joseph Roth writings in order to highlight the ambivalence of the idea of political order, to which the author bestows a high adoration as a source of historical sense, although he also dooms the effects of technological progress. Finally, Musil's notion of insufficient reason will provide the framework able to grasp an experience of the crisis that will not lead to nihilism. The main purpose of this paper is to study the poetic side of the political and historical patterns, suggesting a connection between the faculty of judgment, the poetry and the history.
\end{abstract}

Keywords: Habsburgic Myth, Crisis, Philosophy of History, Stefan Zweig, Franz Werfel, Joseph Roth, Robert Musil.

\title{
1. Introducción
}

Resulta cuando menos llamativa la tendencia de la historia a llamar en defensa de sus tesis y descubrimientos a una facultad tan veleidosa y voluble como la memoria, depósito de experiencias vividas, autora de figuras de contornos variables y objetividad poco fiable, testigo solapado e instrumento de un narcisismo básico que el sujeto nunca llega a controlar del todo. ${ }^{1}$ Con frecuencia, el uso del plural

\footnotetext{
1 Ejemplar con respecto a esta cuestión es el escrito de J. Derrida, «Demeure. Fiction et témoignage», en M. Lisse (éd.), Passions de la littérature. Avec Jacques Derrida, Paris, Galilée, 1996. Comentarios
} 
implicado en el sintagma "memoria histórica" pretende disolver la patología introduciendo la clave de la pluralidad, sin caer en la cuenta de que con ello se fortalece su probable desvarío, rodeándolo de la legitimidad de lo compartido y común. Pues, a pesar del célebre fragmento de Heráclito $^{2}$, el decurso histórico confirma de la mano de innumerables ejemplos que la locura se comparte tanto o más que el sentido común o, lo que viene a ser lo mismo, que para el conocimiento cabal de un cuerpo vivo, como lo son todos los cuerpos civiles, resulta tanto o más imprescindible cartografiar los focos de lo patológico como disponer de un diagnóstico firme de las causas de su salud. No hay mejor memoria de lo que uno es que aquella que propician las crisis, un término de origen medicinal -ahí está la krísis de la medicina hipocrática y galénica- que enfrenta al orden de los acontecimientos con su intrínseca trascendencia, a saber, con la necesidad de identificar qué decisiones y operaciones les permitirán seguir siendo lo que son, sin adentrarse en un proceso de transfiguración que podría equivaler a la muerte. ${ }^{3}$ Como recoge Galeno en uno de sus comentarios de los aforismos de Hipócrates, la krísis significa:

un cambio rápido en la enfermedad hacia la salud o hacia la muerte; se produce cuando la naturaleza separa lo perjudicial de lo favorable por la secreción. ${ }^{4}$

bien sugerentes sobre el mismo se encontrarán en J. Santos, «Política y ficción. Hipótesis para una valoración política de la deconstrucción derridiana», Revista filosófica de Coimbra 44 (2013), especialmente pp. 374s. Vd. definición de la imaginación en Aristóteles, De anima, III 3, 427 b17ss.: «Es evidente $[\ldots]$ que la imaginación no consiste ni en inteligir ni en enjuiciar. Y es que aquélla depende de nosotros; podemos imaginar a voluntad -es posible, en efecto, crear ficciones y contemplarlas como hacen los que ordenan las ideas mnemotécnicamente creando imágenes-, mientras que opinar no depende exclusivamente de nosotros. [...] [L]a imaginación no puede ser tampoco ninguna de las disposiciones habituales o potencias a las que siempre acompaña la verdad, como son la ciencia o el intelecto».

2 Heráclito, fragmento 5 (89 D-K): «Que para los que están despiertos hay un mundo u ordenación único y común o público [héna kaì koinòn kósmon eînai], mientras que de los que están durmiendo cada uno se desvía a uno privado y propio suyo», trad. por A. García Calvo.

${ }^{3}$ Me parece ejemplar la definición del término «crisis» elaborada con ayuda de la investigación psicoanalítica freudiana por J.L. Villacañas en «Crisis: ensayo de definición», Vínculos de historia 2 (2013), p. 136: «La crisis, como regresión, no regresa a cualquier sitio. Pone de nuevo encima de la mesa lo que constituía la premisa más oculta de lo que se hunde, aquello que estaba en el origen, lo que vinculaba a los seres humanos con su sistema, y justo ofrece a eso mismo una nueva solución. La crisis en ese sentido se parece a la experiencia de lo siniestro de Freud. Hace surgir aquello que estaba en el origen, pero que se tendía a ocultar, olvidar, reprimir, porque estaba más allá de las estabilizaciones, fundándolas, demasiado estructural como para ser sometido a una decisión reflexiva cargada de riesgos. Lo indisponible ahora en la historia es la imposibilidad de garantizar la irreversibilidad». Cfr. el clásico mapa histórico-conceptual de R. Koselleck, «Crisis» en Id., Crítica y crisis. Un estudio sobre la patogénesis del mundo burgués, Madrid, Trotta, 2007, pp. 241-281.

4 Galeno, In Hippocratis aphorismos commentarii, K. 17b 470; cfr. In Hippocratis prognosticum commentarii, K. 18b 231. 
En el campo de la medicina, el recurso a la krísis remite a la semiótica de los signos y síntomas que permiten pronosticar qué relación hay entre el cuerpo dañado y la enfermedad, como un arte de los signos que orienta al sujeto con respecto tanto al progreso del mal como al itinerario que debe recorrerse en caso de retornar a un estado de razonable salud, arrojando como saldo un bien provechoso saber acerca de la propia in-firmitas. 5 Lo crítico anuncia la inminencia de una peripecia determinante en la suerte de algo o de una decisión que resultará de vida o muerte. Y ambos fenómenos suelen estar enlazados, como reconoce la historiografía de Tucídides $^{6}$, que hace de la peste y de la consiguiente stásis ateniense una krísis esencial para el conocimiento que la ciudad tiene de sí misma, en la que el desmoronamiento del nómos exige la emergencia de alguien capaz de despertar phóbos frente a los dioses y aidós hacia las leyes entre la población. En lo que sigue nos ocuparemos de algunas piezas literarias que hacen del mito habsbúrgico la clave de la identidad de una comunidad histórica y lingüística, en torno a la cual autores como Joseph Roth y Robert Musil traen a superficie las tensiones dominantes de una época, en la estela de la Anspannung der Energie que sirviera de pauta para la elaboración de un mapa de tópicos a los grandes romanistas del siglo XX.7 Sirva de ejemplo la obsesión de Musil por lo accidental como único indicio del sistema, conducta que responde justamente a la capacidad de lo micro para conducir directamente a lo «crítico» de una situación 8 , pues todo momento es bueno para tomar conciencia del dominio del principio de razón insuficiente.

\footnotetext{
5 Vd. el magnífico trabajo de I. de los Ríos, «Mórbida crisis, débil gobierno», en L. Cadahia/G. Velasco (comp.), Normalidad de la crisis/Crisis de la normalidad, Madrid, Katz, 2012, pp. 18ss.

6 «El pronto disfrute de las cosas y lo agradable» se instituyó como lo honorable, sostiene Tucídides en Historia de la guerra del Peloponeso, II, 52. Vd. los comentarios de L. Cadahia sobre el sentido doble, medicinal y jurídico del término krísis, «El dispositivo de la crisis como nuevo orden mundial», en ibid., p. $177 \mathrm{~s}$.

7 Más allá del trabajo de H.-U. Gumbrecht, Vom Leben und Sterben der grossen Romanisten. Karl Vossler, Leo Spitzer, Erich Auerbach, Werner Krauss (München, C. Hanser Verlag, 2002), nos parece imprescindible en castellano la lectura del trabajo de A. de Murcia, «Teoría literaria de la Romanistik y mitologías de la Weltliteratur», en J. Morales Mena (comp), Teoría de la literatura. Restos, Lima, Ed. San Marcos, 2012, vd. especialmente pp. 35ss.: «Aplicada al conocimiento histórico de una cultura literaria, el objetivo de esta estilística es identificar la capacidad del autor para concentrar las tensiones de una tradición, para operar en su propia obra un «tensionamiento de energías» (Anspannung der Energie), que el romanista también debe experimentar si quiere ser capaz de conocer su obra».

8 Vd. M. Cacciari, Paraíso y naufragio. Musil y el hombre sin atributos, Madrid, Abada, 2005, pp. 2122: «Pero el que capta la realidad según la perspectiva de su Unvollkommenheit y sus contradicciones como signo de un porvenir que urge, y que sólo en los angostos límites de la estadística es posible delinear, puede al fin comprenderla de modo más fuerte y riguroso que el simple «realista». Esa especial sensibilidad que le permite advertir en todo caso su radical falta de fundamento, y presagiar sus futuras metamorfosis, le permite describir también con gran realismo lo «crítico» de la situación o, mejor dicho, saber que el «punto crítico» está en todas partes. Esta «sabiduría» del hombre sin atributos le da a toda la novela su tonalidad de fondo. Ulrich es precisamente el que se mueve por dentro de todos los pliegues de la historia, mostrando, en cada palabra y en cada silencio, que el punto de ruptura puede aparecer en cualquier sitio, que en cualquier sitio «el sistema» puede sufrir un colapso».
} 


\section{El Imperio austro-húngaro como prueba de la desconocida raíz común de poesía e historia}

El desvencijamiento del inmenso aparato político-administrativo, eminentemente simbólico, en que había consistido el Imperio austro-húngaro dio comienzo a una de las fases melancólicas más productivas de la historia europea. Un texto célebre de Stefan Zweig podría oficiar como divisa del espíritu elegíaco despertado por el proceso de demolición:

Cuando intento encontrar una fórmula práctica para el tiempo que precedió a la Primera Guerra Mundial, en el que crecí, confío en ser lo más preciso cuando digo que fue la edad dorada de la seguridad. Todo en nuestra milenaria monarquía alemana parecía estar fundado en la perdurabilidad y el Estado mismo el garante supremo de esta estabilidad. Los derechos que otorgaba a sus ciudadanos eran ratificados por el Parlamento, representante del pueblo elegido libremente, y cada deber estaba rigurosamente delimitado. [...] Cada cual sabía cuánto poseía o cuánto le correspondía, lo que estaba permitido y prohibido. Todo tenía su norma, su vara de medir y peso determinados. Quien tenía un patrimonio podía saber exactamente cuántos intereses arrojaba anualmente; el funcionario, el oficial, encontraba de manera fiable en el calendario el año en el que se promocionaría o se jubilaría. [...] Este sentimiento de seguridad era la posesión más ambicionada por millones de personas, el ideal de vida común. [...] Hoy aceptamos que la palabra ,seguridad“ ha sido borrada desde hace tiempo de nuestro vocabulario como un fantasma, sonreímos ante la locura optimista de aquella generación deslumbrada por los ideales, según los cuales el progreso técnico de la humanidad tiene que tener como consecuencia un ascenso moral igualmente rápido. Nosotros, que hemos aprendido en nuestro siglo a no dejarnos sorprender por ninguna explosión de bestialidad colectiva; nosotros, que esperamos que el día de mañana esté más perdido que el anterior, somos significativamente escépticos con respecto a una educación moral de los hombres. ${ }^{9}$

\footnotetext{
9 S. Zweig, El mundo de ayer. Recuerdos de un europeo, Barcelona, Acantilado, 2001, pp. 15-19. Cfr. W. M. Johnston, El genio austrohúngaro. Historia social e intelectual (1848-1938), Oviedo, KRK, 2009, pp. 117-123. Debe reconocerse la capacidad de Zweig para reconocer otros modelos de orden distintos del europeo. Puede acudirse para ello a su espléndido ensayo Brasil, país de futuro (Madrid, Capitán Swing, 2012), y concretamente a la siguiente descripción de Rio de Janeiro, pp. 198-200: «[T]odo se confunde en las calles, alegremente, y, gracias a la multitud de fisonomías distintas, la calle se transforma en un cuadro en constante mutación. ¿Qué arte de disminuir las tensiones sin, por ello, destruirlas! ¡De conservar la multiplicidad sin el menor deseo de poner orden en ella y de organizarla por la fuerza! Que se siga cultivando tal arte en esa ciudad, que no se deje arrastrar por el delirio geométrico de las avenidas rectilíneas, de las intersecciones exactas, por ese ideal tan feo de convertirse en tablero que persiguen las modernas ciudades del ritmo acelerado, que, a favor de la línea recta y de la monotonía de las formas, oprimen lo que siempre es lo incomparable de cualquier ciudad: sus sorpresas, sus peculiaridades, sus angulosidades y, sobre todo, sus contrastes entre lo moderno y lo antiguo, entre la ciudad y la naturaleza, entre los pobres y los ricos, entre la laboriosidad y la holgazanería, cuya solución armoniosa, única en el mundo, se goza libremente en Rio de Janeiro».
} 
Otro pasaje, no menos conocido, de otro autor austríaco, Robert Musil, pone el acento en su evocación de un Estado ya hundido, desaparecido, como Kakania, en la capacidad de ese organismo para mantenerse en la densidad de lo no-realizado, que devuelve al espectador la impresión de que todo estaba bañado «con el soplo húmedo de los océanos de donde ha surgido la humanidad», como si nada tuviese unos contornos del todo nítidos en el interior de la arquitectura barroca de un organismo dotado de una curiosa autorregulación:

El gobierno era clerical, pero el espíritu liberal reinaba en el país. Ante la ley, todos los ciudadanos eran iguales, pero no todos eran igualmente ciudadanos. Existía un Parlamento que hacía un uso tan excesivo de la libertad que casi siempre estaba cerrado; pero había una ley para los estados de emergencia con cuya ayuda se salía de apuros sin Parlamento, y cada vez que volvía de nuevo a reinar la conformidad con el absolutismo, ordenaba la Corona que se continuara gobernando democráticamente. De tales vicisitudes se dieron muchas en ese Estado, entre otras, aquellas luchas nacionales que con razón atrajeron la curiosidad de Europa, y que hoy se evocan tan equivocadamente. Fueron vehementes hasta el punto de trabarse por su causa y de paralizarse varias veces al año la máquina del Estado; no obstante, en los períodos intermedios y en las pausas de gobierno la armonía era admirable y se hacía como si nada hubiera ocurrido. Únicamente la aversión que unos hombres sienten contra las aspiraciones de los otros (en la que hoy estamos todos de acuerdo), se había presentado temprano en este Estado, se había transformado y perfeccionado en un refinado ceremonial que habría podido tener grandes consecuencias, si su desarrollo no se hubiera interrumpido antes de tiempo por una catástrofe. 10

El texto de Musil añade al de Zweig la lucidez del conocimiento de las circunstancias de la catástrofe, a saber, la confianza en la función purificadora del estallido de una crisis. ${ }^{11}$ Kakania ha suministrado a sus pueblos los medios para cultivar el sentido de lo super-real [das Überwirkliche], elemento del que proceden todos los acontecimientos mundanos. El tejido de Kakania se encontraba inflamado, como un organismo mostrenco, por múltiples simulacros ${ }^{12}$ que afectaban a la vida

\footnotetext{
10 R. Musil, El hombre sin atributos, I, Barcelona, Seix Barral, 2010, pp. 36-37.

11 Nos ha resultado sumamente útil la lectura del trabajo de Ana Carrasco-Conde, «Blow up. Evento, acontecimiento, crisis», Cadahia y Velasco, op. cit. (nota 5) (p. 3), y muy especialmente su tratamiento de la distinción entre acontecimiento y evento, vd. p. 135: «[S]i un acontecimiento puede ser forzado y con ello introducido en forma de simulacro en el sistema, la irrupción del evento, debido sobre todo a su carácter "externo", levanta las capas de la historia como si fueran escamas y nos permite ver así lo que hay debajo. Literalmente, nos "descoloca" y es este desajuste el que posibilita un cambio de perspectiva y la distancia suficiente para entender retrospectivamente algunos acontecimientos del pasado. Ante la irrupción de un evento, si este produce una crisis, se pregunta, por ejemplo, qué es lo que falló en el modelo anterior para que en el tejido de la historia irrumpiera lo inesperado».

12 Vd. J. Baudrillard, «La precesión de los simulacros», en Id., Cultura y simulacro, Barcelona, Kairós, 2008.
} 
política, administrativa y social de su territorio, pero que también estaban dotados de expedientes pensados para salir airosos de estados de emergencia, probando que el no-ser puede resultar un sólido cimiento. Poco podían hacer, sin embargo, esos injertos ante la catástrofe puesta en marcha por la obsesión de llevar a cabo la fantasmática Acción paralela, que paradójicamente se proyecta como el mejor homenaje que los súbditos del Imperio podrían rendir al fundamento de su existencia civil. Toda la actuosa trama de preparativos que, en forma de atropelladas e intensas comisiones y asambleas se pone en marcha para consumar ese deseo, confirma con su colapso precisamente aquel que el sistema político del Imperio ofrece a todo ciudadano que se interese por su hechura interna. ${ }^{13}$ La Acción patriótica es un espejo nada distorsionador de la circunstancia política de cualquier ciudadano de Kakania, donde, como se lee al final de Las tribulaciones del joven Törless, la única ciencia es la de que todo ocurre [alles geschieht], sin que el proyecto logre imponerse al accidente y la concomitancia.

Sin embargo, nosotros los hombres pertenecemos a una especie que ama el orden, y que sólo construyéndolo se siente en casa, como expresa el imperativo de nostalgia de Novalis. Aun con el coste de encubrir entidades teratológicas bajo el mascarón de la normalidad. En ese contexto, la experiencia de la crisis introduce una mediación existencial necesaria en esa querencia14, al generar la transición que va del fruto tomado de la naturaleza al artefacto de la técnica. Es bien sabido que la melancolía, como todos los comportamientos pulsionales, no destaca por llorar la pérdida de bienes reales. Sencillamente, se lamenta por la pérdida de algo acostumbrado y que había llegado a considerarse como una segunda naturaleza irrenunciable, sin tener por qué acertar en la estimación que se le reserva. Joseph Roth, en un tono cercano al de Zweig, se duele, por ejemplo, porque ya no haya espacio para el

13 Johnston 2009, op. cit. (nota 9), pp. 155-156: «En las décadas anteriores a 1914, la clase media fue la que más sufrió a causa de la tediosa marcha de una administración cuyo lema era «puede esperar». El papeleo y las complicaciones burocráticas ya eran legendarios; en Viena, las gestiones de pago de impuesto pasaban por manos de veintisiete funcionarios cada una. Hacia 1905, un encargado del ferrocarril a quien se juzgaba por negligencia fue absuelto cuando su abogado apareció en la sala con treinta tomos declarando que «la disposición que mi cliente está acusado de no haber respetado se encuentra en alguna parte entre estos treinta volúmenes». La lotería estatal, fundada en 1787, estaba pensada para consumir los ahorros de los pobres dándoles el aliciente de que pagando más podrían ganar cantidades mucho más elevadas».

14 El planteamiento que G. Lukács impone en Teoría de la novela a la relación entre sujeto y mundo en la historia de la literatura occidental sigue resultando, a mi entender, magistral y válida (Barcelona, Grijalbo, 1970, pp. 331-332): «Cuando lo anímico de las formaciones no se puede ya convertir directamente en alma, cuando las formaciones mismas no aparecen ya como acumulación y depósito de interioridades que en cualquier momento se pueden retransformar en alma, tienen que conseguir una fuerza que domine a los hombres ciega, arbitraria y universalmente, si es que han de seguir subsistiendo. Y los hombres llaman leyes al reconocimiento de la fuerza que los esclaviza, y la desesperada omnipotencia y la universalidad de su dominio se transforma para el conocimiento en el concepto de la ley, y se sublima en la sublimadora logicidad de una necesidad ajena al hombre, eterna e inmutable». 
recuerdo en la civilización de la velocidad y el acero, en la que el arte de la narración, como había diagnosticado con extrema perspicacia W. Benjamin, se reduce a un pálido reflejo del servicio que prestó a nuestra especie y su experiencia del paso del tiempo. ${ }^{15}$ El melancólico declara su enemistad al inexcusable paso del tiempo. Pero si abrimos algo más el objetivo de la cámara, advertiremos que el objetivo del sentir saturniano, la mítica Kakania, encerraba bajo escenografías como la obediencia militar y el eficaz despacho del funcionario, a saber, los cauces de mediación principales entre el emperador y el pueblo, pasiones como la inoculación de un miedo mucho más poderoso hacia el superior que hacia el enemigo, como si de alguna manera el fatigado aparato institucional habsbúrgico fuese intuitivamente consciente de que la matriz del mal -como en El desierto de los bárbaros de Buzzati- yacía en el interior, en el descontento e indignación de alguna de las más de doce nacionalidades sometidas al águila bicéfala del Emperador, un símbolo igualmente consagrado al dios de la ambivalencia. Freud levanta acta de esa conducta enfermiza tras su participación en unas maniobras militares:

Todos los oficiales envidian a los de su misma graduación, abusan de sus subordinados y temen a sus superiores, y cuando más ascienden, más les temen. ${ }^{16}$

Por otra parte, la Schlamperei generalizada ponía fáciles las cosas al enemigo, al que bastaba el soborno para acceder a importantes secretos militares, como recoge el magnífico fresco de la época de W. Johnston. H. Broch, de la mano de su distinción radical entre estética y ética, entre arte por el arte y arte que retorna a su pauta platónica, denominará al corazón de este Imperio corrupto, Viena, «metrópoli del kitsch» 17 y hervidero de un plácido Apocalipsis, consecuencia lógica del vacío de valores de la época. Sin embargo, lejos de toda ironía y sarcasmo ${ }^{18}$, F. Werfel entona una de las elegías del Imperio Austro-Húngaro más cargadas de emotividad

15 J. Roth, La Marcha Radetzky, Barcelona, Edhasa, 2001, pp. 83-84: «Entonces, antes de la gran guerra, $[\ldots]$ no era del todo indiferente que uno viviese o muriese. Si uno era borrado de la fila de los mortales, no entraba en seguida otro en su lugar, para hacer olvidar al difunto, sino que permanecía un hueco en el que aquél faltaba [...]. Todo lo que crecía necesitaba mucho tiempo para crecer, y todo lo que perecía necesitaba mucho tiempo para ser olvidado [...]; se vivía en el tiempo de los recuerdos, como hoy se vive gracias a la capacidad de olvidar rápido y enérgicamente». Vd. los comentarios de R. García Alonso sobre el anacronismo militante de Roth, en García Alonso, R., Ensayos sobre literatura filosófica, Madrid, Siglo XXI, 1995.

16 Citado en Johnston 2009, op. cit. (nota 9), p. 165.

17 Vd. H. Broch, «Hofmannstahl y su tiempo», cap. I, en Id., Poesía e investigación, Barcelona, Seix Barral, 1974, p. 140; cfr. H. Arendt, «H. Broch (1886-1951)», en Id., Hombres en tiempos de oscuridad, Barcelona, Gedisa, 2001, especialmente pp. 125-148.

18 Acerca de la legítima pertenencia de la corrupción a todo cuerpo político vd. las lúcidas reflexiones de J. Santos sobre la inviabilidad de alcanzar «una pureza política asegurada «por sistema»» a partir de la deconstrucción de Derrida 1996, op. cit. (nota 1), pp. 379-380). 
en el prólogo a su colección de relatos Aus der Dämmerung einer Welt. A su juicio, el Imperio de Francisco José encarnaba la única idea política capaz de reprimir y superar las energías demónicas motrices del mito del Estado nacional y, con ello, resultaba portador de una salud que la Primera Guerra Mundial arrebató a Mitteleuropa. En efecto, el César austro-húngaro carecía de personalidad, habría sido también un hombre sin atributos, carente de una personalidad concreta, precisamente por su aspiración a representar todas. ${ }^{19}$ Los estados nacionales -sostiene Werfel- siempre se encuentran amenazados, tanto como resultan amenazadores para entidades salvíficas como los imperios, deseosos de «establecer el dominio de Dios sobre la tierra». ${ }^{20}$ La tensión emocional del propagandista busca conmover el ánimo del lector recurriendo a instrumentos que recuerdan a un Chesterton que hubiese perdido su legendaria ironía y alcanzando sus cotas de máxima construcción ideológica en la afirmación del carácter trascendente de la idea imperial frente al inmanentismo demónico de los nacionalistas checos, húngaros y serbios, hecho de sangre y tierra, o en el canto a la paz garantizada por la costumbre del emperador de recurrir al arte del fortwusteln como táctica disuasoria frente a sus ministros y generales, desconocedores de Solferino y ávidos de guerra. A lo largo del texto al que aludimos la anábasis platónica destaca como operación teórica dominante, por medio de la cual se eleva un tribunal sobre la historia, que permite elogiar lo virtuoso y condenar lo corrupto:

$[\mathrm{N}]$ osotros, los seres humanos, estamos destinados a no comprender nunca el momento presente, a menos que gustemos de interpretar la Historia, esto es, el pasado. Sólo lo muerto y enterrado, lo consumado, está claro. Comenzamos a adivinar la verdad solamente cuando ha abandonado la forma terrena de sus manifestaciones. De otro modo, aquel mundo no hubiese sido nunca destruido. ${ }^{21}$

A la luz de estos presupuestos platónicos, compartidos con la teoría del valor de H. Broch, el imperio norteamericano, nuevo hogar para el exiliado Werfel, será

\footnotetext{
19 Vd. Johnston 2009, op. cit. (nota 9), pp. 123-135. Vd. la consonancia con el aforismo de F. Grillparzer, datado en 1855 «Der Weg zur neueren Menschheit geht von der Humanität durch die Nationalität zur Bestialität».

20 F. Werfel, Aus der Dämmerung einer Welt/El crepúsculo de un mundo, Barcelona, 1973, p. 10. J. Roth se pronuncia en unos términos mesiánicos muy semejantes a los de Werfel en una carta a S. Zweig, de julio de 1935, desde el hotel parisino Foyot, vd. J. Roth, La filial del infierno en la Tierra, Barcelona, Acantilado, 2012, p. 194: «No creo en «la humanidad». No he creído nunca en ella, sino en Dios, y en que la humanidad, sin Su merced, es un pedazo de mierda. Pero confío en Su merced. «Palestina», «humanidad», son términos que desde hace tiempo me repugnan. Sólo me importa Dios, y de momento, en la tierra, como entorno en el que puedo trabajar y en el que he de cumplir mi misión terrenal, un Imperio católico alemán. Eso, en la medida de mis débiles fuerzas, procuraré conseguirlo por medio de los Habsburgo».
}

21 Werfel 1973, op. cit. (nota 20), p. 34. 
comparado con un «gran horno de combustión rápida», laboratorio de procesos mecánicos, mientras que Austria vendría a ser «el campo de cultivo que absorbe y transforma lentamente» 22 la heterogeneidad que encuentra a su alrededor, como cabe esperar de todo organismo. Esta cocción de larga duración era el escenario más adecuado para sortear las enérgicas decisiones que aconsejaban las reclamaciones nacionalistas de los pueblos integrantes del imperio mediante el recurso al célebre fortwursteln, toda una lección de cadencia temporal:

Ante toda esta dinámica de odio, oponía él [el emperador] una sagaz y magnífica resistencia pasiva: una técnica maestra de retrasar, de evitar el conflicto y dejar que se resolviese por sí solo. Los irreverentes austriacos dieron un nombre a esa política, inventando la clásica frase fortwursteln, un concepto parecido al dicho popular de «capear el temporal». [...] Entonces ocurrió la catástrofe de Sarajevo. [...] Los generales que desplegaban su genio en los ejercicios de maniobra, vieron que había llegado el momento de ahora o nunca. Los ministros de inteligencia feudal, cansados de juicios fortwursteln se alegraron de asumir el tono de los «hombres fuertes de Prusia».23

Sin duda, la figura imperial, núcleo de un entramado de lentitud e ineficacia generalizadas, era la más adecuada para desempeñar la función de un rostro jánico: el gran culpable o el gran inocente. Y el elegíaco autor de La canción de Bernardette opta decididamente por la segunda figura. Pero la implacable semblanza historiográfica de W. Johnston hace saltar por los aires la crisálida literaria del aparato burocrático de Francisco José, elevado por K. Kraus al célebre estatuto del Bürokretinismus:

La propensión de los servicios administrativos hacia la lentitud engendró el llamado «absolutismo atenuado por Schlamperei», cuyas lagunas hacían que la vida fuera llevadera en lo que de otra forma habría sido un estado opresivo. Tras 1880, las formalidades burocráticas proliferaron de tal manera que inhibían no ya la innovación, sino también la propia rutina. El estancamiento fue el único resultado posible del intercambio incontrolado de favores, aquello que Taaffe calificaría de «salir del paso» (fortwursteln). Actuando de manera incompetente, el régimen sólo logró provocar su propia actitud crítica que luchaba por silenciar [...]. A pesar de las apariencias, que los presentaban como un bastión de unidad y estructura, los burócratas austríacos cometieron tremendos errores, que provocarían una catástrofe en el resto de Europa. ${ }^{24}$

\footnotetext{
22 Ibidem, p. 14.

23 Ibidem, p. 24. Sobre el fortwursteln puede acudirse también a Musil 2010, op. cit. (nota 10), p. 369: «Divagación segunda: la ley de la historia -pensó entonces- no es otra que el principio estatal del «Viva la Pepa» [fortwursteln] en la antigua Kakania. Kakania fue un Estado extraordinariamente cuerdo».

24 Johnston 2009, op. cit. (nota 9), p. 160.
} 
El lento y mastodóntico sistema burocrático habsbúrgico, encargado de propiciar el inmovilismo social-Sozialbeharren- preconizado por Metternich25, contenía una mezcolanza de factores burgueses y feudales que dificultaban la emergencia de una verdadera Modernidad. Nada podía oponerse más en realidad al espíritu de la burocracia analizada por los hermanos Weber, para la que -Lukács dixit- «el objeto del interés y de la actividad es inmediato, y solamente inmediato». ${ }^{26}$ Se trataba de un organismo envejecido y enfermo, cuyos sucesivos ensayos de idealización ni siquiera eran capaces de suscitar una reaparición simbólica de su antiguo poder y violencia en la historia. Sencillamente, otros factores, demasiado flotantes para identificarse con ningún organicismo, se habían apoderado del ambiente y, con ello, del campo de la historia.

\section{Joseph Roth y la dilogía del orden: la denuncia de la gravedad y el anhelo de la gracia}

Musil y Roth actúan como portavoces de reacciones muy diferentes ante el desmoronamiento del orden habsbúrgico, fenómeno que despierta en el segundo una melancolía ansiosa de la llegada del milagro, mientras que en el primero ocasiona el descubrimiento de fuerzas subterráneas encubiertas por el barroco mascarón del Imperio. 27 Entre los recuerdos reunidos por Soma Morgenstern es conocido el disgusto que la lectura de la Kakania de Musil generó en Roth ${ }^{28}$. Pero la idealización del mundo de ayer no debe ensombrecer que La marcha Radetzky contiene una de las denuncias más implacables de la manipulación de la historia, singularizada en el hiato que separa la vivencia del héroe de Solferino, Joseph Trotta, y la descripción que los manuales de historia de los Gimnasios austriacos recogen del episodio, con

\footnotetext{
25 Vd. C. Magris, Il mito absburgico, Torino, Einaudi, 2009, p. 124. Cfr. H. Von Srbik, Metternich. Der Staatsmann und der Mensch, München, 1925, vol. I, p. 350.

26 G. Lukács, «Tribuno del popolo e burocrate?» (1940), en Il marxismo e la critica letteraria, Torino, Einaudi, 1953, p. 221.

27 Vd. J. Le Rider, «Arbeit am Habsburgischen Mythos. Joseph Roth und Robert Musil im Vergleich», en W. Amthor/H.R. Brittnacher (Hrsg.), Joseph Roth - Zur Modernität des melancholischen Blicks, Berlin/New York, W. de Gruyter, 2012, p. 23.

28 Vd. S. Morgenstern, Huida y fin de Joseph Roth, Valencia, Pre-textos, 2000, p. 103: «Una década más tarde, quizá ya en el año 1938, en París, me preguntó un emigrante austríaco si Roth había leído El hombre sin atributos. Había más gente sentada en nuestra mesa y también estaba Roth, que escribía, pero oyó la pregunta y se apresuró a responderla él mismo: "He leído un buen trozo con gusto. Pero cuando, después de millares de páginas, llama a Austria Cacania, otra vez Cacania y dale con Cacania, he parado. ¡Es repelente!”». Roth denominó a la I República un «flamante Estado, pero lamentablemente parcheado con viejos tablones K.K.», como recoge su biógrafo D. Bronsen, Joseph Roth. Eine Biographie, Köln, 1974, p. 198. Cfr. O.G. García, «La conversión a la «idea austríaca» de J. Roth», Anuario de estudios filológicos 14 (1991), pp. 143-148.
} 
evidentes fines propagandistas, sin que el testimonio del protagonista de la acción pueda apelar a ninguna autoridad superior al principio que la Poética de Aristóteles había elevado a regla de oro de cualquier relato, a saber, «lo imposible verosímil se debe preferir a lo posible inverosímil». Joseph Trotta no encuentra más que indiferencia, cuando no desprecio, ante su protesta por el desajuste existente entre su propia experiencia y el relato construido a partir de ella. Un secretario del ministro de instrucción le explica que la heroicidad de Solferino se ha reformulado respondiendo a «la capacidad de comprensión de los estudiantes», que, por otra parte, se acomoda paradójicamente al ejercicio de «transmisión de órdenes» que Ulrich, el hombre sin atributos, vislumbra en su primera divagación sobre la historia. ${ }^{29} \mathrm{El}$ rechazo de Joseph de las mentiras, supuestamente patrióticas, sobre las que se encuentra fundado el Imperio, lo arrojan «del paraíso de la fe en el emperador». 30 Todo ello confirma que el mito habsbúrgico se resuelve probablemente en una rapsodia procedente de transfiguraciones análogas, de lo que realmente ocurrió y de lo que realmente se dijo en sucedáneos fabricados para perpetuar la dominación del pueblo, tradicionalmente tendente a la servidumbre voluntaria. Como decíamos al comienzo, la elaboración poética de la memoria modifica esencialmente el aspecto y el alcance del presente histórico. ${ }^{31}$ La marcha Radetzky levanta acta del intento desventurado de Carl Joseph, el nieto del héroe de Solferino, por remedar a comienzos del siglo XX la hazaña que dotó a su familia del reconocimiento del Emperador, sin

${ }^{29}$ Vd. Musil 2010, op. cit. (nota 10), p. 369: «Divagación primera: Ulrich se acordó de una experiencia de sus tiempos del servicio militar. El escuadrón está compuesto por hombres a caballo, formados de dos en dos; el ejercicio de «transmisión de órdenes» consiste en comunicarse los mandos de uno a otro en voz baja; si el anterior dice: "el sargento preceda a la columna", los siguientes repiten: "sean fusilados inmediatamente ocho hombres", o algo similar. Del mismo modo se forma la historia del mundo».

30 Vd. Roth 2001, op. cit. (nota 10), pp. 14-15: «Joseph Trotta, barón de Sipolje, aceptó malhumorado los dones imperiales como si fueran una ofensa. La campaña contra los prusianos se hizo sin él y perdieron. Trotta estaba rencoroso. Ya empezaban a plateársele las sienes, su mirada perdía brillo, su paso se tornaba lento, pesada la mano, hablaba menos que antes A pesar de hallarse en sus mejores años, parecía como si envejeciera pronto. Expulsado del paraíso de la fe sencilla en el emperador y en la virtud, en la verdad y en el derecho, se hallaba encadenado ahora al silencio y la resignación, por más que se diera cuenta de que la astucia asegura la continuidad en este mundo, la fuerza de las leyes y la fama de los monarcas. Gracias a los deseos del emperador, expresados en alguna ocasión, desapareció la lectura número quince de los libros de lectura para las escuelas del reino. El nombre de Trotta perduró únicamente en los anales secretos del regimiento. El comandante siguió viviendo, portador desconocido de una fama tempranamente apagada, como la sombra fugitiva que proyecta un objeto, escondido en secreto, sobre el claro mundo de la vida». Vd. García Alonso 1995, op. cit. (nota 15), p. 203.

31 Con respecto a la continuación de La marcha Radetzky (Radetzkymarsch) que es La cripta de los capuchinos (Kapuzinergruft) y la enseñanza que se desprende de esa secuencia para la relación entre poesía e historia, puede acudir con provecho a A. Doppler, «Die Kapuzinergruft von Joseph Roth. Österreich im Bewusstsein von Franz Ferdinand Trotta», in M. Kessler/F. Hackert (Hg.), Joseph Roth. Interpretation - Rezeption - Kritik, Tübingen, 1990, p. 97. 
conseguir generar nada que no sea más que su esperpento. El sueño de Solferino se alterna con el sueño de Sipolje, encarnación momentánea de la felicidad en territorio ruteno, en Ucrania: Carl Joseph fantasea tanto con la proyección de dejar su huella en los manuales de historia como con la salida de ella, dedicándose al cuidado del terruño esloveno perteneciente a su familia. Pero el estallido de la Primera Guerra Mundial modifica radicalmente la inclinación de la balanza:

Era la guerra, para la que se había preparado desde los siete años. Era su guerra, la guerra del nieto. Los días y los héroes de Solferino retornaban. 32

El deseo de consumar su anhelo épico le conduce a creer que el fuego enemigo no puede golpearlo, de suerte que «el sentimiento de seguridad e inviolabilidad» 33 que Freud asociara con las figuras heroicas de la literatura le lleva al sacrificio, no por salvar esta vez la vida de Francisco José, sino por llevar dos humildes cazos de agua a soldados de infantería ucranianos que tiene a su cargo. ${ }^{34}$ En cualquier caso, la heroicidad alberga siempre una dimensión vergonzante, tanto la del abuelo como la del nieto, aunque el tono elevado de la primera contrasta con la humildad de la segunda. La literatura de Roth puede considerarse una elegía dedicada a la pérdida de vínculos. Es habitual que en ella se dibuje con caracteres melancólicos y sombríos a los soldados que vuelven del campo de batalla -los Kriegsheimkehrer-convertidos en fantasmas desprovistos de todo vínculo social. Tal es el caso del oficial austriaco Tunda, huido de un campo de prisioneros ruso. Se trata de un perfecto hombre sin atributos - sin empleo, sin amor, sin deseos, sin esperanza, sin ambición-, la representación de la superficialidad, el desarraigo y el desmoronamiento sobre la tierra. 35 El mero contacto visual con la gran ciudad -con Berlín- le vuelve consciente de su falta de preparación, física y espiritual, para el fenómeno de «siniestra locura racional» [unheimlich vernünftigen Wahnsinn] rastreable en una urbe semejante a la Metrópolis de George Grosz:

Vimos en unos pocos días: un loco homicida y una procesión; una première cinematográfica; un rodaje; el salto mortal de un artista en Unter den Linden; un hombre que había sido atracado; el asilo para los sin techo; una escena de amor en el Tiergarten a plena luz del día; columnas de anuncios rodantes, movidas por burros; trece locales para

\footnotetext{
32 J. Roth, Werke, Bd. V, «Romane und Erzählungen», F. Hackert (Hrsg.), Kiepenheuer \& Witsch, Köln 1989-91, p. 438.

33 Vd. S. Freud, «Der Dichter und das Phantasieren», in Id., Studienausgabe, Bd. X, Frankfurt a.M., 1969-1975, p. 176.

$34 \mathrm{Vd}$. la lúcida lectura sobre las paradojas internas al desenvolvimiento histórico en la literatura de Roth de J. Heizmann, «Mythen und Masken. Figuren- und Wirklichkeitsgestaltung bei Joseph Roth», in Amthor y Brittnacher 2012, op. cit. (nota 27), pp. 185-186.

35 Roth, Fuga sin fin, Barcelona, Acantilado, 2003, p. 167.
} 
parejas homosexuales y lesbianas; una pareja normal, tímida, entre las 14:00 y las 16:00, que marcaba su nombre en los troncos de los árboles y era multada por un guarda, por haber causado daños a un bien público; un hombre que pagaba una multa por haber atravesado un plaza en lugar de permanecer en la esquina derecha; una manifestación de la secta de amantes de las cebollas y el ejército de salvación. ${ }^{36}$

La descripción bizarra y desencantada de un espectáculo recuerda a las decepcionadas postales que desde el París revolucionario, Heinrich von Kleist enviara a sus familiares y amigos. ${ }^{37}$ La misma estructura urbana berlinesa parecía «una confusión ordenada, una arbitrariedad planificada, un despropósito dotado de finalidad aparente, jamás tanto orden se asemejó al desorden», declara Roth en La pétrea Berlín. Y tampoco titubea a la hora de mostrar la confusión que produce en él la nueva arquitectura urbana, en la que un cabaret puede llegar a parecer un horno crematorio y todos los locales destinados al ocio dependencias mortuorias. ${ }^{38}$ Ningún corazón, y menos el de un judío de los confines orientales del Imperio Austro-húngaro, en busca de los lazos perdidos, podía estar a la altura de esta «sinfonía de la gran ciudad», de semejante caleidoscopio de sensaciones incompatibles con arreglo a los límites bien definidos a los que se refería Zweig en sus recuerdos de un tiempo perdido. La visión de un policía de tráfico en el Berlín de 1924 conduce a Roth a la delirante visión de una nueva deidad pagana en medio de Potsdamerplatz, producto del culto y la idolatría al automóvil. ${ }^{39}$ Kraus había asociado el hundimiento

\footnotetext{
36 Roth, Werke, Bd. IV, «Romane und Erzählungen (1916-1929)», F. Hackert (Hrsg.), Kiepenheuer \& Witsch, Köln 1989-91, p. 465. Vd. comentarios de Heizmann, ibídem, p. 214ss.). Cfr. G. Simmel, El individuo y la libertad, Barcelona, Península, 1986, p. 396: «La atrofia de la cultura individual por la hipertrofia de la cultura objetiva es un motivo del furioso odio que los predicadores del más extremo individualismo, Nietzsche el primero, dispensan a las grandes ciudades»; cfr. R. García Alonso, Ensayos sobre literatura filosófica, Madrid, Siglo XXI, 1995, pp. 178ss.

37 Werke und Briefe, S. Steller/P. Goldammer/W. Barthel/R. Loch (Hg.), Bd. IV, Aufbau-Verlag, Berlin/Weimar, 1978, p. 265: «Cada fiesta nacional cuesta de media la vida a diez hombres. Ello se prevé con seguridad a menudo, sin que se prevenga la desgracia. En la fiesta del armisticio del 14 de julio se elevó un globo en la noche con un aro de acero en la parte superior, en el que se habían colocado fuegos artificiales que se encendían en el aire, de manera que el globo quedase encendido. El espectáculo era bello, pero era de prever que, cuando el globo fuera presa de las llamas, el aro caería sobre el campo, que estaba atestado de hombres. Pero una vida humana es aquí una cosa de la que se tiene 800.000 ejemplares -el globo se elevó, el aro cayó, hirió de muerte a unos cuantos, y no ocurrió nada más».

38 Roth, «Arquitectura» (1929), en El juicio de la historia. Escritos 1920-1939, El juicio de la historia. Escritos 1920-1939, Madrid, Siglo XXI, 2004, p. 248.

39 Vd. J. Roth, El juicio de la historia, ibid., p. 218: «Es más que un soberano. Su tribuna es más que un trono. Sobrecogido por la imponente estatua y poderío del hombre, se me ocurre de repente que no dirige el tráfico, sino que lo oficia, su pedestal de madera es un púlpito, en derredor suyo tiene lugar el servicio divino de la nueva era. Con devoción piadosa, los vehículos se detienen ate una señal de su dedo índice. Si los automóviles tuvieran rodillas, se postrarían ante él. Tengo la visión de un nuevo servicio divino, probablemente un servicio idólatra. Percibo el sonido del órgano pagano-caótico de los vehículos polifónicos, el sonido impaciente, perentorio, admonitorio, suplicante de las bocinas que
} 
del Titanic con la venganza ex machina del dios de los idólatras del maquinismo. ${ }^{40}$ En semejante ambiente, el antiguo súbdito del Imperio sólo podía practicar una huida sin final. Al trasladarse a París, Tunda comprenderá que en la nueva era el dinero ha sustituido a la estabilidad de los nexos ausentes, de suerte que hasta los escritores militantes de izquierdas dependen del sueldo que les proporciona el patrón burgués de los periódicos para los que escriben. Nadie es propiedad de sí mismo, pero no por ello dejan de difundir la especie, un anhelo romántico más, de que los ideales pueden apoderarse de las fuerzas responsables de la realidad circundante, y en esta crítica acerca de la efectividad del ideal coincide completamente con el escepticismo práctico de Musil. Por su parte, el ocio manifiesta que las gentes viven sujetas a roles quiméricos que el cine y la prensa convierten en populares, de suerte que todos viven en la irrealidad - «in einer Unwirklichkeit leben» ${ }^{41}$, en una densidad flotante compuesta de deseos, clichés y constructos poéticos, como los empleados analizados por S. Kracauer. En semejante coyuntura histórica lo trágico se traslada del personaje o héroe al destino histórico que éste sufre. Así lo argumenta Roth en una carta a Zweig, que había leído la anti-odisea de Franz Tunda:

[S]iempre he tenido y tengo prevención contra ese «trágico» tradicional, me parece que ese hombre de la posguerra tampoco tiene ya la «clásica» capacidad para la tragedia, y que ésta se traslada del «carácter» y se instala en la «observación histórica». Es decir: podemos ver una tragedia genérica en el destino que sufre un hombre de posguerra à la Tunda. ${ }^{42}$

Mientras tanto, la emergencia del fondo bestial de la humanidad progresa de 1914 a 1933, ante la indiferencia del mundo y la proliferación de pretextos vergonzantes de su necesidad:

El embotamiento del mundo es mayor que en 1914. El hombre ya no se conmueve cuando se vulnera y asesina la condición humana. En 1914 desde todas partes se esforzaba uno por explicar la bestialidad con razones y pretextos humanos. Pero hoy en día se pertrecha a la bestialidad con explicaciones bestiales, que son aún más atroces que las propias bestialidades. 43

son como los gemidos y aullidos de los condenados. Tengo la visión del nuevo Dios al que todo esto atañe, un Dios de acero, hierro, electricidad, nitrógeno y valores bancarios». Sobre la panorámica urbana que ofrecía el Café Josty de Potsdamer Platz y el tráfico descrito con potencia mítificadora por Roth puede acudirse a E. D. Weitz, Weimar Germany. Promise and Tragedy, Princeton/Oxford, Princeton U.P., 2007, pp. 42-44.

40 Vd. K. Kraus, «Grosser Seig der Technik» (1912), in Id., Untergang der Welt durch schwarze Magie (1922), Werke, Bd. 8, München, 1960, p. 51. Citado por Johnston 2009, op. cit. (nota 9), pp. 885-886.

41 Roth (nota 36), p. 492. Vd. Heizmann 2012, op cit. (nota 34), pp. 215-216.

42 Carta de J. Roth a S. Zweig, 24 de enero de 1928, en J. Roth, Cartas (1911-1939), Barcelona, Acantilado, 2009, pp. 149-150.

43 Vd. carta de J. Roth a S. Zweig de marzo de 1933, Roth 2012, op. cit. (nota 20), p. 187. Vd., en la misma recopilación, el artículo de Roth, publicado en julio de 1933 en Das Neue-Tagebuch sobre la 
No falta en Roth la conciencia de la caducidad de la realidad captada por la escritura ${ }^{44}$, al tiempo que no duda en adoptar un tono mesiánico cuando se trata de intervenir directamente en el decurso histórico, al aconsejar sustituir la militancia por la pesquisa del bien, allí donde éste se halle, sin acepción de personas ni de ideologías políticas:

Podemos, aunque con dificultad y esfuerzo, marcharnos de los países cuya nacionalidad arrastramos. Pero de la época en la que hemos nacido jamás podremos escapar, a no ser mediante la muerte. Tanto si vamos a la «izquierda» a la «derecha» o nos quedamos en el «centro», tanto si vestimos de rojo, verde o azul, tanto si hablamos indostaní o calmuco: todos somos hijos de nuestro tiempo, hemos sido marcados por él, es más, marcados a fuego. Nuestra época es nuestra patria. Nuestros «hombres de Estado» deberían denominarse hombres de la época. Y nuestro deber, nuestra ley, nuestro futuro no es otro que actuar, establecernos, por tanto, en aquellos sectores en los que sabemos que el bien tiene su morada y desde los que escuchamos su llamada. Incluso nuestra época tiene uno de esos sectores. Ésta sería nuestra patria, la verdadera. ¿Tener una patria? No se trata de eso. Sólo se tiene una patria cuando se la encuentra, es decir, cuando se ha escuchado la llamada del bien. ${ }^{45}$

Así escribe J. Roth en la Pariser Tageszeitung en enero de 1939, buscando desesperadamente la apertura en el decurso histórico de la gracia capaz de conducir a la humanidad a un destino no autodestructivo. La conservación del mito habsbúrgico responde a la voluntad de experimentar la gracia, como el anciano judío Job hará al reencontrarse con su pequeño tullido Menuhim, convertido ya en flamante director de orquesta, tras la travesía del desierto espiritual que supone el exilio neoyorquino.

polémica entre Klaus Mann y Gottfried Benn a raíz del nombramiento del último por los nazis como nuevo director de la Academia Prusiana de las Letras, p. 18: «Un asesino que mientras tira al suelo a su víctima le suelta una conferencia sobre la sed natural de sangre de un asesino nato, despierta incluso en la víctima la sospecha de que se trata de un teórico del asesinato que le está matando a golpes, pero no de un verdadero asesino. En una situación así, cuánto mejor aquel Hobler, el ministro, que dijo que allí donde se cepilla la madera, tienen que volar astillas. ¡Vuelta de una metáfora a la sangrienta realidad y justificación de la realidad por medio de una metáfora!».

${ }^{44}$ Las ciudades blancas (Minúscula, 2009) de Roth, citado por E. G. Bera, «Prólogo» a J. Roth, El juicio de la historia. Roth 2004, op. cit. (nota 38), p. 13., pp. x-xi: «El buen observador registra la voz de lo instantáneo en su entorno. Pero no sabe que otras voces suenan, después de que él ha dejado su lugar de escucha. Y antes mismo de que lo anote, ese mundo que él conoce ya no es el mismo. Mientras escribo esto, Marsella ha cambiado. Y lo que cuento con mis palabras es una gota sacada del océano de los acontecimientos, que no puede verse a simple vista, trémula en la punta ligera de la pluma».

45 Roth 2012, op. cit. (nota 20), p. 165. 


\section{Lo que acontece y su fantasma. La poética de lo real en R. Musil}

La mirada que Musil dirige a la realidad identifica en ella la eficacia de un motor poético que aparece como la fuerza dominante en el orden de los hechos y en el orden de las ideas. La precedencia de la posibilidad relativiza cualquier época y explica el cambio de mentalidad que distribuye los tiempos:

Ideas, que antes parecían de escasa validez, adquirían consistencia. Personas sin mayor relieve se hacían famosas. La aspereza se pulía, divergencias tornaban a converger, los independientes pactaban con el éxito, el gusto ya definido volvía a hacerse inconstante. Las líneas fronterizas, enérgicamente trazadas, eran borradas en todas partes, y una nueva e indescriptible tendencia a aparentar animaba a gente nueva e inspiraba nuevos conceptos. Estos no eran malos, de seguro; era solamente que se había mezclado demasiado lo malo con lo bueno, el error con la verdad, la acomodación con el convencimiento. Esta mezcolanza parecía existir en composición con una quinta esencia, con un sucedáneo que, a pesar de su humildad, bastaba para hacer que el genio apareciera verdaderamente genial, y un talento auténtica promesa, así como, según algunos, sólo una cierta dosis de cebada o de achicoria es suficiente para dar al café la verdadera esencia de café. De repente, los más privilegiados e importantes puestos del espíritu quedaron ocupados por gente de tal género, y todo se decidía a su modo. La culpa no la tenía nadie, ni se puede describir cómo había ocurrido todo eso. Sería injusto acusar a personas y atribuirlo a ideas o a determinados fenómenos. No era falta de ingenio ni de buena voluntad, como tampoco de caracteres; era falta tanto de todos como de nadie; se diría que la sangre o el aire se había mudado, una enfermedad misteriosa había destruido la pequeña genialidad de un principio, pero todo resplandecía con un nuevo fulgor $y$, al final, no se sabía si el mundo había empeorado realmente o más bien había envejecido. En ese momento, empezó por fin una nueva era. ${ }^{46}$

La adopción de semejante punto de vista dirige la atención del novelista hacia una aureola fantasmal que logra explicar con mucha mayor nitidez los hechos que su pretendida secuencia cronológica. Y ello se cumple justamente porque cada presente parece estar dominado por un subsuelo de simulacros cuya presencia sólo se comprende y calibra en un periodo de crisis, que deformando la realidad abra espacio para las figuras monstruosas inherentes a ella que no permitía observar la presunta normalidad. Musil se decanta por la captación de la esencia fantasmal -el eídolon- de una época antes bien que por la hipertrofia de la memoria como instrumento de penetración en los estratos de tiempo concentrados en el presente:

La explicación real de lo real no me interesa. Mi memoria es mala. En efecto, los hechos son siempre intercambiables. Me interesa el elemento espiritualmente típico, querría decir incluso: lo fantasmático de lo que ocurre. ${ }^{47}$

46 Musil 2010, op. cit. (nota 10), pp. 61-62.

47 Musil, «Was arbeiten Sie? Gespräch mit Robert Musil», entrevista con O.M. Fontana, in R. Musil, 
Musil no se preocupa por la introspección psicológica, sino que persigue el aislamiento de «das Zwischen-ihnen»48, de lo que ocurre alrededor de los protagonistas de la acción narrativa. Si hay una temporalidad que la obra maestra de Musil quiere desencubrir es el brotar múltiple de la posibilidad, cuya emergencia amenaza en todo momento a la ingenua creencia en lo racioide de los acontecimientos. E1 protagonista, Ulrich, al que el autor pensó denominar en un principio Anders, pues la profundidad de su reflexión le conduce siempre a la otredad, aspira a mirar de frente a la matriz ontológica de la posibilidad, es decir, la potencia ambivalente que es la urdimbre de todo lo real, regida por el «principio de razón insuficiente» 49 que atraviesa a la subjetividad, visibilizando sus propios cambios de trayectoria:

Tagebücher, Aphorismen, Essays und Reden, ed. por A. Frisé, Hamburg, 1955, p. 785. Musil se presenta a sí mismo como «ein Unzufriedener» (Drei Frauen, Hamburg, 1959, 148), consciente de la ineptitud del espíritu capitalista para abrir nuevas expectativas para el presente, pero demasiado conservador para comulgar con la acción revolucionaria. Cfr. Buridans Österreicher (1919). Cfr. Magris 2009, op. cit. (nota 25), p. 307: «Sentido austriaco, habsbúrgico de las posibilidades, por tanto; ¿y qué otra cosa es la Acción paralela sino la garbosa y divertida sátira de la incapacidad austriaca de elegir y de querer? Un gran comité se reúne para preparar los festejos con ocasión del septuagésimo aniversario de la subida al trono de Francisco José, y en competencia tácita con los preparativos germánicos para honrar aquel mismo año a Guillermo II. El motor de toda la trama de la novela es la búsqueda afanosa de una «idea» para la Acción paralela. [...] Se piensa en una vigorosa manifestación expresada por el seno del pueblo y guiada desde lo alto, en una Austria mundial modelo de una armonía concorde de los pueblos, en una síntesis de alma y capital, o bien en un Congreso mundial de la paz, en una política pacifista basada en el refuerzo de los armamentos... El compromiso secular de la política habsbúrgica asume las proporciones de un ballet irónico, y la sabiduría superior de esta mediocritas, convertida en mito tantas veces, es subvertida como un guante y retorcida en un nudo».

48 Vd. G. Baumann, «Robert Musil - Die Struktur des Geistes und der Geist der Struktur», Germanisch-Romanische Monatsschrift X/4 (1960), p. 438. Vd. los comentarios de J. Casals acerca de la obra mayor de Musil como una «gran summa», compuesta por los tipos constituyentes de una época, en J. Casals, Afinidades vienesas. Sujeto, lenguaje, arte, Barcelona, Anagrama, 2003, pp. 316ss. Vd. Magris 2009, op. cit. (nota 25), pp. 311-312: «La indagación psicológica venía, así, a la luz de estas intenciones a disolverse; lo que contaba era «lo espiritualmente típico», capturado en los varios personajes, que venían a configurarse como las caras de un prisma, los diversos lados prospectivos de una entidad sociológica. Su ansia de totalidad no permitía a Musil titubear sobre contingencias particulares, dirigirse a la individualidad; y el Todo orgánico que quería captar era algo al mismo tiempo sociológico y religioso. Sociológico era el tono dominante de la cultura y de los problemas de una sociedad; religioso, por la gran parte reservada a la inquieta indeterminación del «alma», y sobre todo por el esfuerzo de superar el elemento temporal contingente, para desembarcar en la orilla del Absoluto, para alcanzar la gran Unidad. Así, Clarisse se afana para conseguir una mística consonancia con la vida del universo; así, Ulrich persigue en el amor de la hermana la perfecta fusión amorosa, el Reino Milenario»».

49 Musil 2010, op. cit. (nota 10), pp. 139-140. Vd. L. Dhan-Gaida, Musil. Saber y ficción, Buenos Aires, Nueva Visión, 2007, p. 182: «Musil transfiere a lo posible aquellos atributos que Leibniz asigna a lo real -el máximo de perfección y Bien-. A partir de entonces, lo valorizado es la pluralidad de mundos como tal». 
[C]abría definir el sentido de la posibilidad como la facultad de pensar en todo aquello que podría igualmente ser, y de no conceder a lo que es más importancia que a lo que no es. Como se ve, las consecuencias de tal disposición creadora pueden ser notables; es así como, por desgracia, aparece no pocas veces falso lo que los hombres admiran, y aquello que prohíben, lícito, o bien ambas cosas como indiferentes. Tales hombres de la posibilidad viven, como se suele decir, en una tesitura más sutil, etérea, ilusoria, fantasmagórica y subjuntiva. Cuando los niños muestran tendencias semejantes se procura enérgicamente hacerlas desaparecer, y ante ellos se califica a esos individuos con los apelativos de ilusos, visionarios, endebles y pedantes o sofistas. 50

El hombre sin particularidades - der Mann ohne Eigenschaften- carece de referentes sólidos -la profesión, el carácter- que dirijan sus pasos y concedan una figura estable a su vida. Lejos de ello, el «teorema del amorfismo humano», formulado por el estudioso de Mach que fue Musil en un escrito de 1923 -«El alemán como síntoma»- encuentra una multiplicidad cambiante de factores, en los que conviven la historia, la ciencia y la vida, a la base de cualquier acontecimiento. Esa multiplicidad matricial explica que «el ser humano se adapt[e] tan fácilmente a la antropofagia como a la crítica de la razón pura» 51 , pues si las circunstancias -ese aglomerado de pequeñas diferencias- lo favorecen, la energética antropológica avanzará sin reticencias hacia una u otra alternativa. La indeterminación y la ambivalencia resquebrajan así la solidez de cualquier ethos pretendidamente estable, y actúan como el fundamento no-racioide de lo racioide. 52 Nada podía oponerse más a la teoría del valor de Broch y a su idealización de figuras como Hofmannstahl, que ante el vacío de valores dominante decide volverse uno con su obra y su estilo, «símbolo en el vacío, no del vacío». 53 Nada refleja mejor que la crisis permanente en que

50 Musil 2010, op. cit. (nota 10), p. 18.

51 Ibidem, p. 369.

52 La proximidad entre las disquisiciones sobre la posibilidad de Musil y la teoría de la temporalidad en Schelling recogida en las tres versiones de Las edades del mundo salta a la vista. Recomendamos a este respecto la lectura de Ana Carrasco-Conde, «Estratos del tiempo. O sobre la efectividad del pasado», en A. Carrasco-Conde/A. Gómez Ramos (eds.), El fondo de la historia. Estudios sobre Idealismo alemán y Romanticismo, Madrid, Dickyinson, 2013, p. 68: «Para Schelling no es la acción al ser hecha la que conforma por acumulación el Pasado, sino que el Pasado es lo que posibilita el presente. [...] Dicho de otro modo, el pasado no es algo dejado atrás, estático, fosilizado o cristalizado, sino que ejerce una fuerza real como fundamento activo de las acciones; y el presente, por tanto, como tiempo de la efectividad, se sostiene sobre él porque es quien le abre las posibilidades y porque además constituye la base sobre la que se erige y se mantiene en pie a través de una tensión constante: el presente es siempre un «estar a la contra» (al. Gegenwart)» y p. 73: «El pasado nunca queda atrás. El pasado nunca queda pasado. Lo que observamos en el tiempo, cargado por nuestra vida con nuestras vivencias, son acciones que siguen ejerciendo efectos en nosotros (Wirkungen). Son hechos efectivos que, aunque pasados, siguen teniendo efectos, siguen actuando en nosotros y viviendo efectivamente en cada uno de los instantes que nos conforman».

53 Brocht 1974, op. cit. (nota 17), p. 191; Johnston 2009, op. cit. (nota 9), p. 732: «Sabiéndose el último de su especie, el quijotesco Broch se mató a escribir, luchando por convencer a las élites del empo- 
se encuentra sumergida en todo momento la Acción Paralela, con su multiplicidad de titubeantes y fantasmáticas expresiones, la terca confianza en las construcciones ideales y su fracaso para construir sólidos vínculos con lo real. A pesar de la unidad de la intención - una celebración a la altura del 70 cumpleaños del Emperador-, la dispersión de los proyectos sugeridos es la mejor manifestación de lo que ocurre en una época de transición. Detengámonos en la descripción de la experiencia de la Entfremdung frente a cualquier tesis y principio de Ulrich, poco antes de que le sea confiado el cargo de secretario honorífico de la Acción Patriótica por parte del conde Leinsdorf:

El espíritu ha experimentado que la hermosura le hace a uno bueno, malo, tonto o seductor. Descuartiza a una oveja o a un penitente y encuentra en ambos humildad y paciencia. Examina una sustancia y reconoce que, en grandes dosis, es un veneno; en pequeñas, un estimulante. Sabe que la membrana de los labios es afín a la de los intestinos y que la humildad de estos labios es también afín a la humildad de todo lo santo. El espíritu deshace, revuelve y cohesiona nuevamente. Bueno y malo, arriba y abajo, son para él conceptos de escéptica relatividad, pero miembros de una función, valores dependientes del conjunto en el que se encuentran. Ha deducido de los siglos que los vicios pueden transformarse en virtudes y las virtudes en vicios y considera una ineptitud que uno no consiga en el curso de su vida hacer de un criminal un hombre de provecho. No reconoce prohibición ni licitud, pues todo puede tener una propiedad por la que un día entre a rodar en un gran engranaje nuevo. Sin darse a conocer, odia a muerte todo lo que aparenta ser inamovible, los grandes ideales y las leyes y su pequeña impronta petrificada, el carácter pacífico. No considera nada firme, ningún yo, ningún orden. Debido a que pueden cambiar cualquier día nuestros conocimientos, no cree en ataduras y para él todo posee el valor que solamente dura hasta el siguiente acto de creación, como un rostro al que se habla y que cambia a cada palabra. ${ }^{54}$

Las propuestas realistas del conde Leinsdorf, del director de banco Leo Fischel o del jefe de sección Tuzzi, férreos defensores del statu quo, para dar contenido a la Acción Paralela se revelan víctimas por partida doble de su propia miopía. Por un lado, desconocen por completo cuán avanzado se encuentra el proceso de desintegración interna de Kakania. Por otro, no calibran suficientemente el peligro inherente al fanatismo de la utopía de quienes, como Diotima, preconizan la movilización total de las energías en aras de la conservación del orden. Ninguno de ellos dispone del más mínimo sentido de la posibilidad que les permita comprender que la realidad se les escapa, que habitan micromundos recortados sobre el fondo de lo

brecimiento que les había acarreado la pérdida de la trascendencia. Sus doctrinas no sirvieron ni para mitigar su propio abatimiento ni para salvar a un mundo cuya muerte lloraba. Como una profecía que tiende a cumplirse por su propia naturaleza, su metafísica platónica arrojó un halo de luz mortecina sobre lo poco que quedaba de la visión leibniziana».

54 Musil 2010, op. cit. (nota 10), p. 159. 
posible. 55 Pues el orden debe ser generativo, esto es, no acomodarse en la repetición, sino decidirse siempre por nuevas soluciones. ${ }^{56}$ Lo único concreto que hay en la Acción se compone en realidad de una lista de nombres: «Emperador pacífico, piedra angular de Europa, Austria auténtica, capital y cultura» ${ }^{57}$. Ésa es la secuencia de términos que el conde Leinsdorf dicta a su secretario para que redacte la circular que pondrá en marcha un perverso mecanismo de negociaciones, comités y asambleas que no logran decidir nada, víctimas de su inconsciencia del principio de razón insuficiente. Frente a la displicencia con que Zweig o Roth tratan a los signos de desmoronamiento del orden representado por la vieja Kakania, Musil hace del ensayo-novela la pieza necesaria para superar el punto de vista de la unilateral racionalidad científica, dadora de orden y medida, y aproximarse a la Überwirklichkeit, donde las ideas y sentimientos cambian continuamente, espacio del arte y de la moral creadora. ${ }^{58}$ La oposición real entre lo racioide [Ratioïd] y lo místico-artístico destaca especialmente de la mano de las imágenes del hombre entero y del orden movible de Goethe, ya inviables en la realidad social y cultural multiversal del hombre sin particularidades, una época crítica:

Eso ya no se da [el hombre entero]. No tienes más que echar una ojeada al periódico. Está lleno de una inmensa opacidad. Se habla de tantas cosas que ni la inteligencia de Leibniz sería capaz de abarcarlas. Pero nadie se da cuenta; hemos cambiado. Ya no existe un hombre completo frente a un mundo completo, sino que un algo humano se mueve en un común líquido nutritivo. 59

55 Vd. Cacciari 2005, op. cit. (nota 8), p. 59: «El hecho es que ninguno de ellos posee el menor sentido de lo posible. Como los fanáticos, por otra parte: éstos manifiestan exclusivamente un infinito sentido de la realidad y del deber, aquéllos un inexacto sentido de la realidad. Los fanáticos no saben salir de la prisión del mundo como es salvo fingiéndose ideales; los realistas se imaginan que desde el corazón mismo de esta prisión se abren maravillosas y progresivas vías de libertad. En su conjunto, figura grotescamente invertida respecto de aquella a la que intentarán dar vida los Hermanos, inseparablesnunca-unidos ellos forman el mundo de las visiones del mundo. Faltándoles todo el sentido de lo posible, todos y cada uno de ellos carecen de ironía. Careciendo de ironía, dependen del azar y no saben llevar a cabo ninguna investigación sobre sus órdenes, sobre sus regularidades. Los realistas siguen operando como si el Yo fuera todavía calculable-salvable, y es más: piensan que su reino todavía está en pie, aunque ya no sobre las sólidas razones de otros tiempos. Y, fundamentándose en la idea de que su soberanía puede durar todavía, trazan programas, establecen jerarquías, creen en el progreso». Cfr. J. Muñoz, «Los protocolos de un sismógrafo», prólogo a R. Musil, Diarios, Barcelona, Debolsillo, 2009, pp. 12-13.

56 Vd. García Alonso 1995, op. cit. (nota 15), p. 43.

57 Musil 2010, op. cit. (nota 10), p. 92.

58 Vd. Casals 2003, op. cit. (nota 48), p. 325: «La diferencia entre Musil y Mach es que aquél no lo reduce todo a los elementos de que se ocupa la ciencia. Como señala el joven Törless, existe una segunda visión que no mira las cosas con los ojos de la razón. Y es esta visión, que corresponde a la esfera del valor, la única que puede arañar lo absoluto. En atención a ello, Musil abandona la ciencia. Y también la filosofía. Si la ciencia despliega una mirada unívoca, la filosofía despliega una mirada totalizadora: los filósofos son «opresores sin ejército» que aprisionan y maniatan la realidad».

59 Musil 2010, op. cit. (nota 10), p. 225. 
El modelo civilizatorio habsbúrgico perece, así, transformando sus formas e instituciones en un «común líquido nutritivo», especialmente por su falta de atención a la «fábrica de alternativas» que escapan a la petrificación de la civilización, por su inoperancia con respecto a la síntesis de elementos heterogéneos, que como ondas y corrientes anulan su eficacia, desprovistos como están de toda mediación, una operación tan esencial para el algo humano como la asimilación de los alimentos. Todos esos elementos se dan cita en un manicomio babélico, que sirve de estancia siempre precaria para una subjetividad en estado de permanente Ichlosigkeit. En ese horizonte, la política se convierte en «una caricatura de la actividad creativa», escribe Musil en su diario, que extrae provecho del griterío, del descontento, de tópicos usurpados a la ética y a la estética, para hacer de la energía de los otros su mejor ariete. Frente a esta política estetizada, la misión del arte deberá señalar dónde se encuentran los límites desde los cuales se constituye un sujeto sabedor de su siniestro y escindido fundamento, a saber, la pareja de la precisión y la indeterminación, el sentido de la verdad y el de la alegoría, la realidad y el presentimiento, entre los que no parece haber solución intermedia, toda vez que si se rinde tributo al uno se desatiende al otro. ${ }^{60}$ Quizá el mismo origen de la condición humana resida en una metáfora ambigua para el entendimiento -productora de la rettende Hemmung auspiciada por Kraus ${ }^{61}$-, pero inequívoca para el sentimiento, que percibe en el desasimiento de las peculiaridades la operación que mejor se acomoda al querer ver y querer percibir lo que oculta la marcha de la historia, un fundamento que sólo la crisis presenta con la violencia de la interrupción.

60 Ibidem, p. 605. Cfr. García Alonso 1995, op. cit. (nota 15), p. 46. Sobre la metáfora en Musil véase A. Gargani, Freud, Wittgenstein, Musil, Shakespeare \& Kafka, 1992, pp. 15-37. Acerca de la ambivalencia que atraviesa la metáfora de la proyección de finalidad que sostiene a toda acción, puede acudirse con provecho al ensayo de A. Valdecantos, «La demora de la ambigüedad. Notas sobre escatología, historia y ambivalencia» en J. Pardos (ed.), Historia y catástrofe, Madrid, Cuaderno Gris, 2012, p. 247: «Que todo final consiste en una mezcla de bienes y males es lo más verdadero que puede saberse sobre los finales, los males y los bienes, aunque la necesidad de juicio y de univalencia sea tan humana como inevitable» y pp. 251-252: «[P]ersistir en la ambigüedad a sabiendas de que lo es y sospechar que puede haberla allí donde pasa inadvertida es una transgresión del régimen normal de las cosas sin la cual resultaría imposible nada que pudiera llamarse pensamiento. Otro tanto ocurre con la mixtura de bien y mal en que consiste el mundo y cualquiera de las sustancias que lo pueblan, y en la que consisten también todos los finales y todos los fines, incluidos los finales de las historias y de los discursos, y desde luego los finales de los discursos sobre la ambigüedad, que tienen forma de fin, pero son tan sólo interrupciones mejor o peor disimuladas aun cuando parezcan el resultado de una cuidadosa premeditación».

61 Sobre Kraus y su conversión del lenguaje en matriz del pensamiento puede acudirse al imprescindible trabajo de S. Santana, El laberinto de la palabra. Karl Kraus en la Viena de fin de siglo, Barcelona, Acantilado, 2011; vd. por ejemplo p. 350:«El escritor, como con frecuencia admitía Kraus, no debe dominar el lenguaje, sino ponerse a su servicio. Al producirse en la cita la muerte de la intención, aparece en ésta lo inexpresable. El origen, por tanto, no se refiere a un espacio definitivo de pureza ideal, sino que consiste en la tarea interminable del crítico, en la duda lingüística que Kraus califica como «entorpecimiento salvador» («rettende Hemmung») frente al progreso que se descubre amenazante en los desastres de la guerra». 